\title{
Effect of phosphate ions on preparation of fly ash based geopolymer
}

\author{
J. K. Sadangi ${ }^{*}$, S. D. Muduli ${ }^{2}$, Dr. B. D. Nayak ${ }^{3}$, Prof. B. K. Mishra ${ }^{4}$ \\ ${ }^{1 *}$ (PGRPE Student, Environment \& Sustainability Dept., CSIR-IMMT, Bhubaneswar, India) \\ ${ }_{2}^{2}$ (DST Women scientist, Environment \& Sustainability Dept., CSIR-IMMT, Bhubaneswar, India) \\ ${ }^{3}$ (Chief scientist, Environment \& Sustainability Dept., CSIR-IMMT, Bhubaneswar, India) \\ ${ }^{4}$ (Director, CSIR-IMMT, Bhubaneswar, India)
}

\begin{abstract}
An experimental investigation was conducted to study the performance of fly ash based geopolymer specimens in Sodium Aluminium Phosphate solution. High strength geopolymer is produced from coal combustion fly ash and sodium aluminium phosphate chemical which can be obtained by hydrated alumina powder reacting with ortho phosphoric acid and sodium hydroxide. The curing is done by both atmospheric and accelerated means. Performance of the specimens was evaluated in terms of visual appearance, change in compressive strength, phase development and micro-structural analysis over the exposure period of time. Evidence is provided with micro structural studies and mechanical strength properties on the presence of amorphous binding phase. These characteristics are similar to alumino-silicate geopolymer.
\end{abstract}

Keywords: Fly ash, geopolymer, Phosphate ions, compressive strength

\section{Introduction}

Geopolymers are inorganic polymeric materials with a chemical composition same as Zeolites but possess an amorphous structure. These are also known as manmade rocks which can be produced by reacting silica alumina rich source material with a highly concentrated aqueous alkaline hydroxide solution or silicate solution. The chemistry of the geopolymer was first discussed by Prof. J. Davidovits in 1999[1]. Geopolymers form three-dimensional network of the tetra-aluminosilicate type with the general empirical formula $\mathrm{Mn}[-$ $\left.\left(\mathrm{SiO}_{2}\right) \mathrm{z}-\mathrm{AlO}_{2}\right] \mathrm{n} . \mathrm{wH}_{2} \mathrm{O}$, in which $\mathrm{n}$ is the degree of polycondensation, and $\mathrm{M}$ is predominantly a mono valent cation $(\mathrm{K}+, \mathrm{Na}+)[1]$.In the same paper, Davidovits states that although the $\mathrm{SiO}_{2} / \mathrm{Al}_{2} \mathrm{O}_{3}$ ratio $\mathrm{z}$ is 1,2 or 3 for the poly(sialate), poly(sialate-siloxo) and poly(sialate-disiloxo) chains, $\mathrm{z}$ can also be larger than 3 (up to 32), which can be explained by cross linking of polysilicate chains, sheets or networks with a sialate link (-Si-O-Al-O-). The fine particle sizes of fly ash, the $\mathrm{Si} / \mathrm{Al}$ ratio, the predominant amorphous structure are appropriate for the synthesis of the geopolymer with a $\mathrm{Si} / \mathrm{Al}$ ratio of 1 or $2[2,3,4]$.

The work presented in this paper deals with the study and investigating the benefit that might be taken from the presence of the phosphate ions. The impact of phosphate ion on strength was studied by preparing geopolymer samples of different concentrations of chemical. Another new feature was the curing to take place at ambient temperatures after accelerated curing of $4-8 \mathrm{hrs}$ at $60{ }^{\circ} \mathrm{C}$. The Fly ash from a major power station was selected and used for this study. The chemical analysis of the fly ash is given in "Table-1".

Table 1: Chemical composition of fly ash in wt $\%$

\begin{tabular}{|c|c|c|}
\hline \multirow{15}{*}{ Major } & Constituents & Concentration, $\mathrm{Wt} \%$ \\
\hline & $\mathrm{SiO}_{2}$ & 59.03 \\
\hline & $\mathrm{Al}_{2} \mathrm{O}_{3}$ & 25.86 \\
\hline & $\mathrm{Fe}_{2} \mathrm{O}_{3}$ & 5.81 \\
\hline & $\mathrm{TiO}_{2}$ & 1.71 \\
\hline & $\mathrm{CaO}$ & 1.07 \\
\hline & $\mathrm{MgO}$ & 0.68 \\
\hline & $\mathrm{K}_{2} \mathrm{O}$ & 1.89 \\
\hline & $\mathrm{Na}_{2} \mathrm{O}$ & 0.07 \\
\hline & $\mathrm{P}_{2} \mathrm{O}_{5}$ & 0.72 \\
\hline & $\mathrm{SO}_{3}$ & 0.14 \\
\hline & LOI $\left(850^{\circ} \mathrm{C}\right)$ & 1.80 \\
\hline & $\mathrm{Cr}_{2} \mathrm{O}_{3}$ & 0.03 \\
\hline & $\mathrm{Rb}_{2} \mathrm{O}$ & 0.01 \\
\hline & $\mathrm{SrO}$ & 0.02 \\
\hline
\end{tabular}




\begin{tabular}{|l|l|l|}
\hline \multirow{4}{*}{ Minor } & $\mathrm{Y}_{2} \mathrm{O}_{3}$ & 0.02 \\
\cline { 2 - 3 } & $\mathrm{ZrO}_{2}$ & 0.05 \\
\cline { 2 - 3 } & $\mathrm{SnO}_{2}$ & 0.02 \\
\cline { 2 - 3 } & $\mathrm{BaO}$ & 0.04 \\
\cline { 2 - 3 } & $\mathrm{CeO}_{2}$ & 0.15 \\
\hline
\end{tabular}

Phosphate bonded geopolymer are synthesized in room temperature and set rapidly like conventional polymer. They represent another variety of mineral geopolymer, where Si is totally or partially replaced by P. They are formed by an acid-base reaction between a metal oxide and an acid phosphate. They have found a wide range of applications such as dental cements, construction materials, oil well cements, and hazardous and radioactive waste stabilization. The main difference between the silicate based geopolymers and phosphate geopolymers, however, is their syntheses. Poly (sialate) geopolymers and their derivates are synthesized in alkaline environment, but phosphate geopolymers are fabricated by acid-base reactions [5]. The formation of such geopolymer is a three-step process. First, oxides dissolve in a phosphoric acid or an acid phosphate solution and metal ions are released into the solution. The aquoions formed from these cations then react with phosphate anions and form a gel of metal hydro phosphates. In the last step, the saturated gel crystallizes into a ceramic [6]. A very wide range of phosphate geopolymers may be synthesized by acid-base reaction between an inorganic oxide and an acid phosphate. The reaction product is generally a poly (hydro phosphate) or an anhydrous poly (phosphate) that consolidates into the product. A good example is Sodium aluminium phosphate which is formed by the reaction between alumina, phosphoric acid and Sodium hydroxide.

\section{Experimental Procedure}

The materials used for making fly ash based geopolymer specimens are low-calcium dry fly ash as the source material, water, and Phosphate ion based chemical activator. The source material used in the production of geopolymer is Class F fly ash obtained from the NTPC, Kaniha, Odisha, having the specific surface area of $120 \mathrm{~m}^{2} / \mathrm{kg}$. The chemical composition of fly ash as determined by X-Ray Fluorescence (XRF) is given in "Table1 ". It can be seen from "Table-1" that the availability of silica and alumina is about more than $80 \%$ of the total mass of fly ash and the ratio of silica to alumina is approximately two.

The chemical binder used was a combination of Aluminium Phosphate and sodium hydroxide solution. The sodium aluminium Phosphate was prepared by reacting hydrated alumina powder with ortho phosphoric acid and Sodium hydroxide. The sodium hydroxide $(\mathrm{NaOH})$ is in flakes or pellet form with $98 \%$ purity. The sodium hydroxide flakes are dissolved in water to make the solution. The chemical solution was mixed well together at least one day prior to use. On the day of casting of the specimens, the solution was mixed together with the extra water to prepare the liquid component of the mixture. The mixture proportion per cube is given in "Table-2".

Table 2: Geopolymer mixture proportions for cube

\begin{tabular}{|c|c|c|c|c|c|}
\hline \multirow{2}{*}{ Materials } & \multicolumn{5}{|c|}{ Mix Design } \\
\cline { 2 - 6 } & $\mathbf{1}$ & $\mathbf{2}$ & $\mathbf{3}$ & $\mathbf{4}$ & $\mathbf{5}$ \\
\hline Fly Ash (Class F), Kg & 7 & 7 & 7 & 7 & 7 \\
\hline Chemical Binder, ml & 140 & 210 & 280 & 350 & 420 \\
\hline Extra Water, ml & 1010 & 940 & 870 & 800 & 730 \\
\hline
\end{tabular}

The fly ash and the liquid component of the mixture were taken together in a pan mixer and the mixing continued for about 4 minutes to get the geopolymer mixture. The mixer was cast into the cubical moulds immediately after the mixing. Temperature is one of the vital tools for geopolymer reaction. So the curing of the cubes made out of different mix design is done by both atmospheric and accelerated $\left(60^{\circ} \mathrm{C}\right)$ means to achieve the desired strength. "Fig-1" and "Fig-2" shows the build-up of strength of the cubes of different mix compositions at different curing condition. 


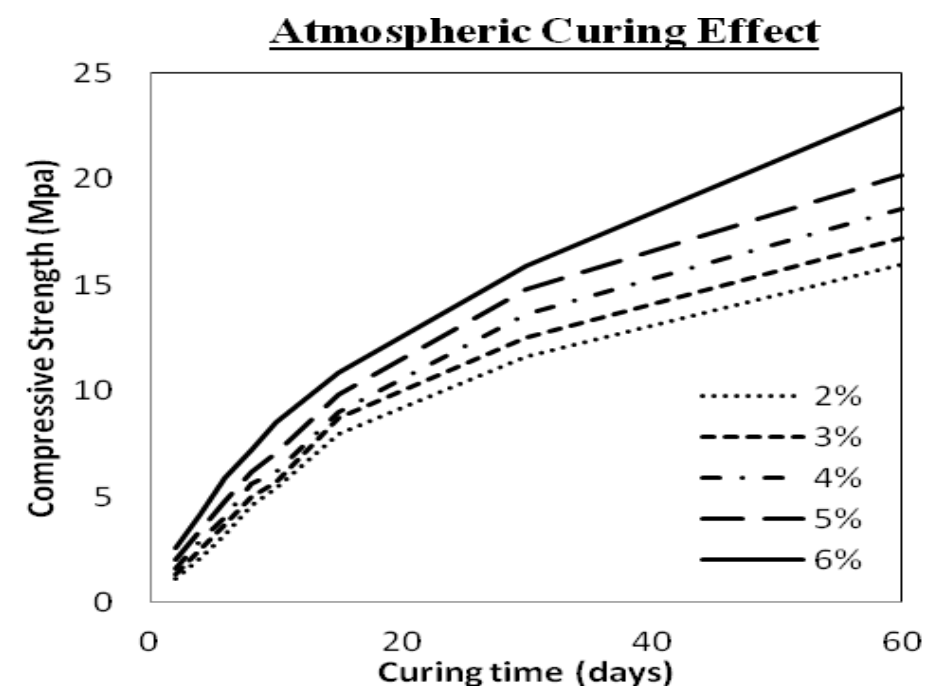

Figure-1: Effect of different concentration of chemcal activator on atmospheric curing

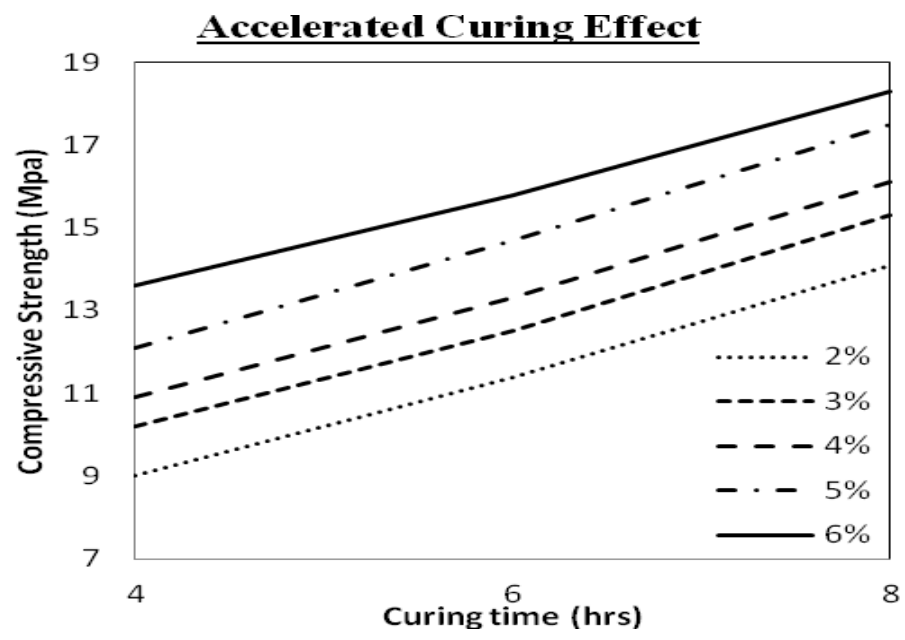

Figure-2: Effect of different concentration of chemcal activator on accelerated curing

After the curing period, the test specimens were left in the moulds for at least six hours in order to avoid a drastic change in the environmental conditions. After demoulding, the specimens were left to atmosphere curing in the laboratory until the day of test. At the end of the curing regime, the specimens were subjected to the compressive strength measurements.

\section{Result And Discussion}

Geopolymer specimens manufactured by activation of low calcium fly ash with an activating mixture of sodium Aluminium Phosphate solution and curing is done by both atmospheric and accelerated means is shown in "Fig-3" and "Fig-4" respectively. These cubes does not show any change in shape and remained structurally intact without any visible cracks. The accelerated cured geopolymer samples show a very little porous structure as shown in "Fig-4".

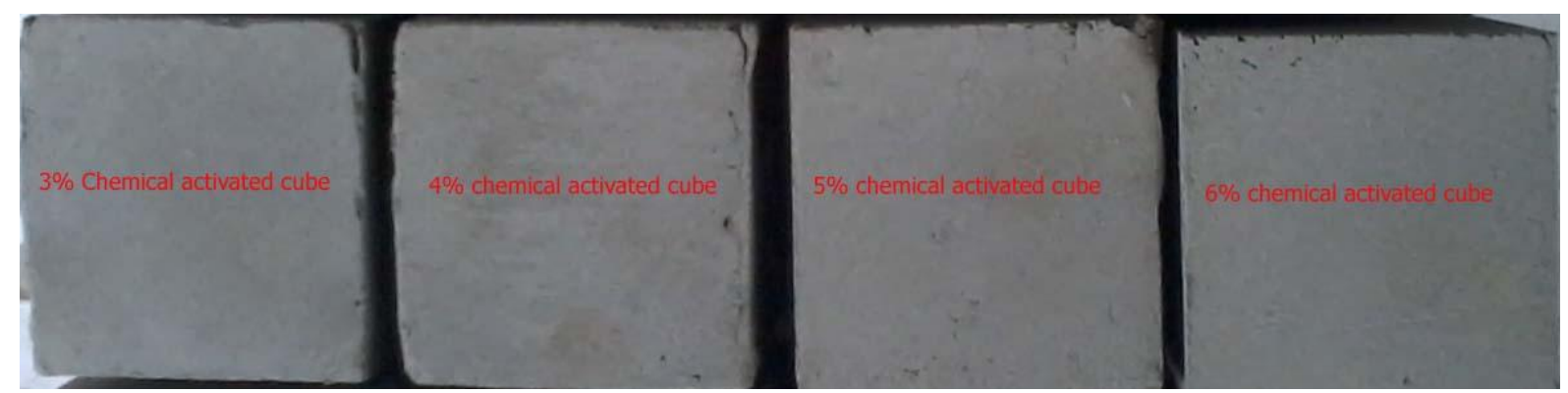

Figure-3: Geopolymer specimens after 60 days atmospheric curing. 


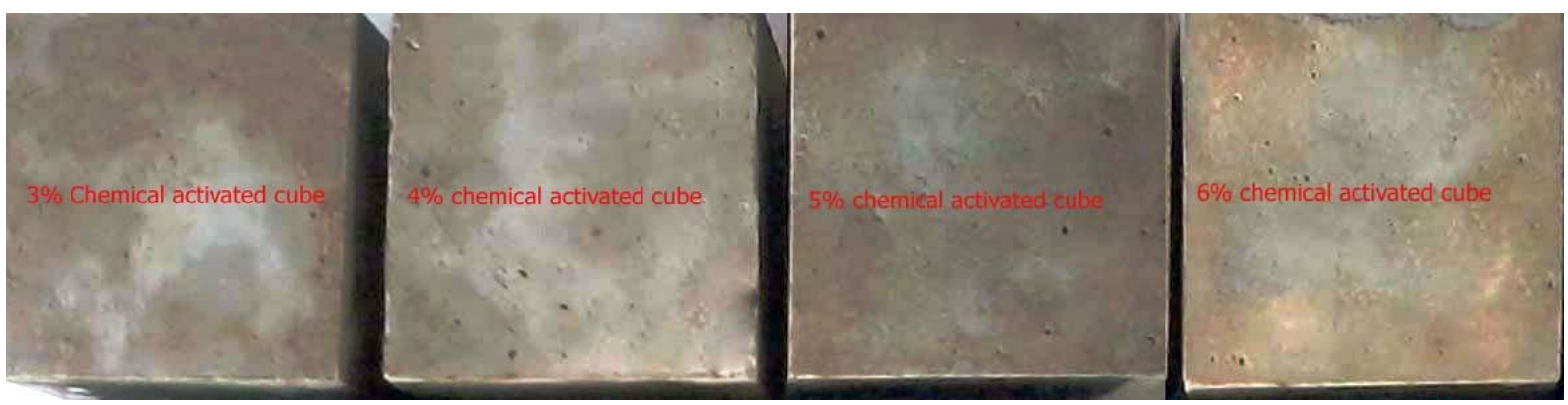

Figure-4: Geopolymer specimens after 8 hours accelerated curing

"Fig-1" and "Fig-2" represents the build-up of strength of the cubes of different mix compositions at different curing condition. During compressive strength test, specimens produce a continuous cracking sound which might be due to crushing of deposited crystals within the pores. From these figure, it has been seen that with the increase in alkaline activator, the strength of fly ash product gradually increases. Also, the strength gradually increases as the curing age increases. So both curing time and curing temperature influence the results for compressive strength of geopolymerization. It was observed that the cube at different alkali ratio attains the maximum crushing strength in 30 to 40 days of atmospheric curing. Due to the application of $60^{\circ} \mathrm{C}$ temperature, polymerization becomes more rapid, and the cube gain $70 \%$ of its strength within 4 to 5 hours of curing time. However, a curing temperature below $60^{\circ} \mathrm{C}$ does not increase the compressive strength [7].

\subsection{Fourier Transform Infrared Spectroscopy (FTIR) Analysis}

The structure and bonding for raw fly ash, atmospheric cured geopolymer and accelerated cured geopolymer was investigated by Fourier Transform Infrared Spectroscopy is shown in "Fig-5". "Table-3 summarizes the IR bands obtained from the FTIR analyses. The IR spectrum of fly ash shows main absorption bands at 1308, 1623, 2345 and $3618 \mathrm{~cm}^{-1}$. The broad component at $1308 \mathrm{~cm}^{-1}$ is due to the $\mathrm{Si}-\mathrm{O}-\mathrm{Si}$ and Al-O-Si asymmetric stretching vibration [8-13] and it becomes sharper and shifts towards lower frequency $\left(1300 \mathrm{~cm}^{-1}\right)$ in geopolymer. Such a shift is understood to be a penetration of $\mathrm{Al}^{4+}$ atoms into the original arrangement of the $\mathrm{Si}$ $\mathrm{O}-\mathrm{Si}$ skeletal structure. Greater the shift of the vibration spectrum, greater the intrusion of $\mathrm{Al}^{4+}$ from raw fly ash into the $\left[\mathrm{SiO}_{4}\right]^{4-}[14]$. This indicates the formation of a new product (the amorphous aluminosilicate gel phase) due to dissolution of fly in alkaline activator [8-13]. Meanwhile, the broad IR bands at $3618 \mathrm{~cm}^{-1}$ and $2345 \mathrm{~cm}^{-1}$ represent the stretching and deformation vibration of $\mathrm{OH}$ and $\mathrm{H}-\mathrm{O}-\mathrm{H}$ groups, respectively, from the weaklybound water molecules that were adsorbed on the surface or trapped in the large cavities between the rings of the geopolymeric products $[15,16]$.

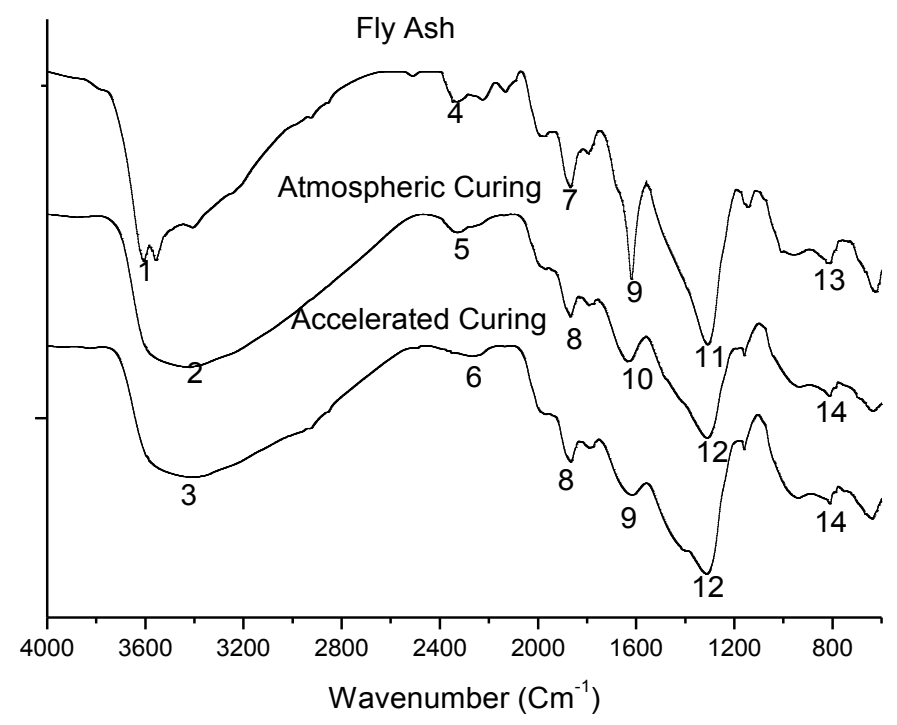

Figure-5: FTIR analysis of Fly ash, Atmospheric curing of $6 \%$ chemical activated geopolymer and Accelerated Curing of $6 \%$ chemical activated geopolymer $\left(1=3618 \mathrm{~cm}^{-1}, 2=3423 \mathrm{~cm}^{-1}, 3=3414 \mathrm{~cm}^{-1}, 4=2345 \mathrm{~cm}^{-1}, 5=2336\right.$ $\mathrm{cm}^{-1}, 6=2302 \mathrm{~cm}^{-1}, 7=1875 \mathrm{~cm}^{-1}, 8=1870 \mathrm{~cm}^{-1}, 9=1623 \mathrm{~cm}^{-1}, 10=1630 \mathrm{~cm}^{-1}, 11=1308 \mathrm{~cm}^{-1}, 12=1300 \mathrm{~cm}^{-1}$, $13=825 \mathrm{~cm}^{-1}, 14=815 \mathrm{~cm}^{-1}$ ) 
Table-3: Development of different bonds at different wave number

\begin{tabular}{|l|l|}
\hline Wave number & Bonds \\
\hline $3750-3400$ & $(-\mathrm{OH})$ stretching of $\mathrm{Si}-\mathrm{OH}$ \\
\hline $2400-2300$ & $(-\mathrm{OH}), \mathrm{H}-\mathrm{O}-\mathrm{H}$ stretching \\
\hline $1875-1869$ & $\mathrm{H}-\mathrm{O}-\mathrm{H}$ stretching due to entrap of water \\
\hline $1620-1650$ & $\mathrm{H}-\mathrm{O}-\mathrm{H}$ bending and presence of $\mathrm{SO}_{4}{ }^{2-}$ and $\mathrm{Cl}^{-}$ \\
\hline 1300,1308 & Si-O-Si and Al-O-Si stretching \\
\hline 815,825 & Si-OH bending and Si-O stretching \\
\hline
\end{tabular}

\subsection{Microstructure Analysis}

The microstructure of the original fly ash based on the SEM observation is shown in "Fig-6". The fly ash consists of spherical, vitreous particles of different sizes. These particles are usually hollow, and some spheres may contain other, smaller particles in their interior [17]. The surface texture of fly ash particles appears to be smooth [18] and also some vitreous, unshaped fragments or quartz particles can be seen [19]. The electron micrograph of a fully reacted solidified fly ash product obtained from $6 \%$ activator solution mixture and curing is done in atmospheric means and accelerated means is shown in "Fig-7" and "Fig-8" respectively.

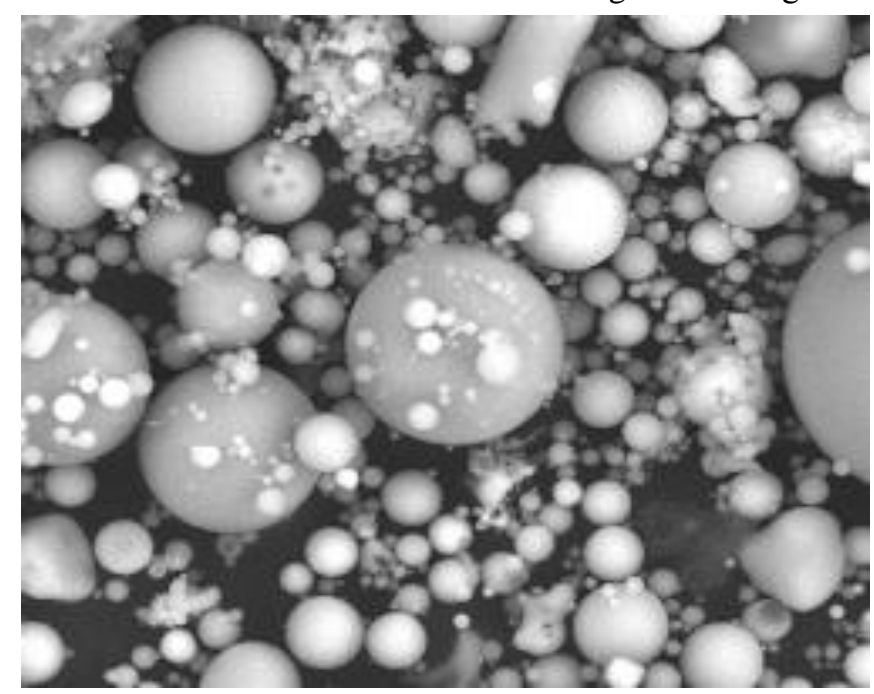

Figure-6: SEM image of original fly ash

Depending upon the bonding strength the geopolymerization process is flexible to make high mechanical strength cubes ranging in crushing strength from 19-23 MPa. In "Fig-7", there is some un-reacted fly ashes are there which results in incomplete geopolymerization reaction and gives low strength product. But as heat is the reaction accelerator, oven drying geopolymer shows complete geopolymerization reaction as shown in "Fig-8" and it gives a relatively higher strength product. 


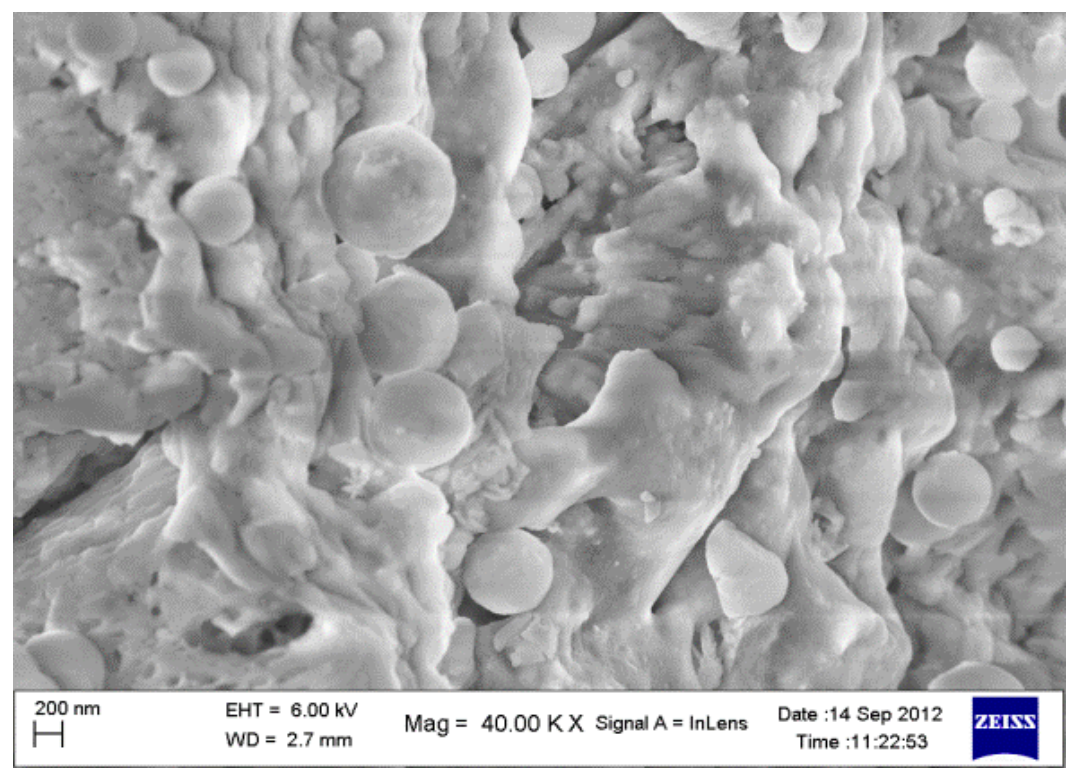

Figure-7: SEM image of atmospheric curing geopolymer

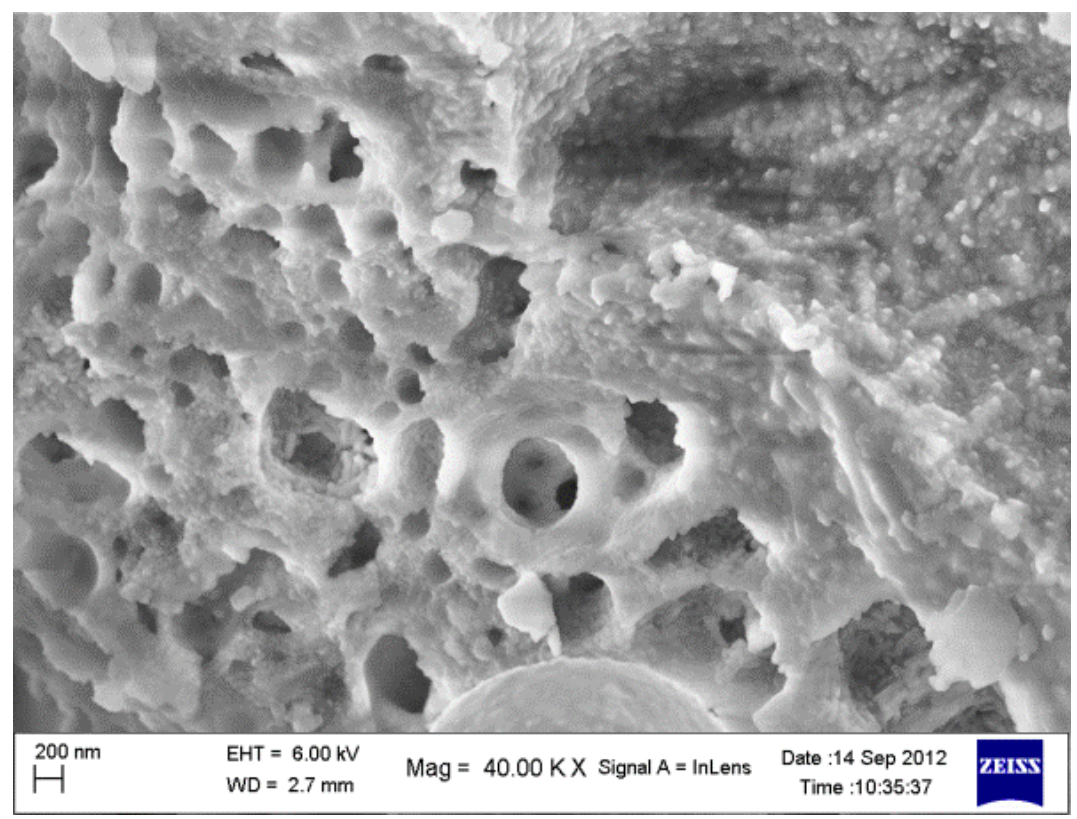

Figure-8: SEM image of accelerated curing geopolymer

\section{Conclusion}

In conclusion, Fly ash based geopolymer which is activated with phosphate bonded chemical activator shows a greater compressive strength compared to other activator. Accelerated cured geopolymer gives more strength and complete geopolymerization reaction compared to atmospheric cured geopolymer. Also, the fly ash to activator ratio plays an important role in the strength development trend. $6 \%$ chemical activator solution gives an excellent result with a compressive strength of $23 \mathrm{MPa}$ after $8 \mathrm{hrs}$ of drying at $60{ }^{\circ} \mathrm{C}$. Phosphate bonded geopolymers are greater suitable for ceramic application.

\section{Proceedings Papers:}

\section{References}

[1] Davidovits J., (1999), Chemistry of geopolymeric systems, terminology, In: Proceedings Second International Conference, Géopolymère '99, Davidovits, J., Davidovits, R. and James, C. (Eds.), Institut Géopolymère, Saint-Quentin, France, 9-39.

[2] Davidovits J., Davidovits R. and James C., (Eds.), (1999), Proceedings Second International Conference, Geopolymère '99, Institut Géopolymère, Saint Quentin, France.

[3] Davidovits J., (Ed.), (2005), Geopolymer, Green Chemistry and Sustainable Development Solutions; Proceedings of the World Congress Geopolymer 2005, Institut Géopolymère, Saint Quentin, France.

[4] Lukey G.C., (Ed.), (2002), Proceedings of the International Conference Geopolymers 2002, University of Melbourne, Australia. 


\section{Books:}

[5] Davidovits J., (2011), Geopolymer Chemistry and Applications, 3rd edition, Institute of Geopolymer, France

\section{Journal Papers:}

[6] Wagh A.S. and Jeong S.Y., (2003), Chemically Bonded Phosphate Ceramics: I. Dissolution Model of Formation, J. Ceram. Soc.,86[11]1838-1844

[7] B.V. Rangan, Low-Calcium Fly-Ash-Based Geopolymer Concrete. Faculty of Engineering (Curtin University of Technology, Perth, Australia, 2008).

[8] Swanepoel, J.C.; Strydom, C.A. Utilisation of fly Ash in a geopolymeric material. Appl. Geochem. 2002, $17,1143-1148$.

[9] Fernandez-Jimenez, A.; Palomo, A. Composition and microstructure of alkali activated fly Ash binder: Effect of the activator. Cem. Concr. Res. 2005, 35, 1984-1992.

[10] Lee, W.K.W.; van Deventer, J.S.J. The effects of inorganic salt contamination on the strength and durability of geopolymers. Colloids Surf. A 2002, 211, 115-126.

[11] Lee, W.K.W.; van Deventer, J.S.J. Structural reorganization of class F Fly Ash in alkaline silicate solutions. Colloids Surf. A 2002, $211,49-66$.

[12] Fernandez-Jimenez, A.; Palomo, A. Mid-infrared spectroscopic studies of alkali activated fly ash structure. Microporous Mesoporous Mater. 2005, 86, 207-214. Int. J. Mol. Sci. 2012, 137198

[13] Criado, M.; Palomo, A.; Fernandez-Jimenez, A. Alkali activation of fly ashes. Part 1. Effect of curing conditions on the carbonation of the reaction products. Fuel 2005, 84, 2048-2054.

[14] Nehdi, M.; Djebbar, Y.; Khan, A. Neural network model for preformed-foam cellular concrete. ACI Mater. J. 2001 , 98, $402-409$.

[15] Palomo, A.; Blanco-Varela, M.T.; Granizo, M.L.; Puertas, F.; Vazquez, T.; Grutzeck, M.W. Chemical stability of cementitious materials based on metakaolin. Cem. Concr. Res. 1999, 29, 997-1004.

[16] Guo, X.; Shi, H.; Dick, W.A. Compressive strength and microstructural characteristic of class c fly ash geopolymer. Cem. Concr. Compos. 2010, 32, 142-147.

[17] Fernandez-Jimenez, A.; Palomo, A.; Criado, M. Microstructure development of alkali-activated fly ash cement: A descriptive model. Cem. Concr. Res. 2005, 35, 1204-1209.

[18] Fernandez-Jimenez, A.; Palomo, A. Characterization of fly ashes, potential reactivity as alkaline cements. Fuel 2003, 82, 22592265.

[19] Fernandez-Jimenez, A.; Palomo, A. Composition and microstructure of alkali activated fly Ash binder: Effect of the activator. Cem. Concr. Res. 2005, 35, 1984-1992. 